\title{
Impact of online reviews on impulsive buying intention based on regulatory focus theory
}

\author{
Zhiguo Fan ${ }^{1, \text { a }}$, Ping Zhang ${ }^{2, b}$
}

${ }^{1}$ School of Management, Tianjin University of Technology, Tianjin, China

${ }^{2}$ School of Management, Tianjin University of Technology, Tianjin, China

azhpingk@126.com, bzhangmkk@sina.com

Keywords: Online reviews, Impulse buying intentions, Regulatory focus theory.

\begin{abstract}
Based on the existing literature combing found online reviews impact on impulse buying intentions. However, previous studies on how it affects the existence of contradictory inconsistent. Therefore, this paper introduces the concept of psychology, regulatory focus theory, trying to study this problem from the inside perspective.
\end{abstract}

\section{Introduction}

Studies have shown that impulse buying makes up a considerable proportion of the retail and even some products accounted for $80 \%$ of the purchase amount. The impulse buying behavior in traditional retail background will also occur against a background of the network. Adelaar (2003) points out that the impulsive purchasing do exist in the network environment, and network shoppers are more compulsive in shopping than online shoppers (Donthu\&Garcia, 1999). With the rapidly development of electronic commerce and the continuous expansion of online shoppers, network impulsive buying behavior research is becoming more and more important. According to the 2013 China's online shopping market research report published by CNNIC, user evaluation dominated in the existing network shopping decisions when people buying unfamiliar goods, and $37.5 \%$ of all online users' main consideration is user evaluation[1]; while in purchases the familiar, the user evaluation still occupy the important position, attach importance to this factor of $25 \%$. So online user reviews, as one of the important tool of consumers' decision-making, has attracted the scholars' attention of how they influence consumers' shopping decisions and their impulsive buying behavior. However, the existing researches only focused on the characteristics of the review (Zhou Xing, 2011), characteristics of the reviewers(Ya-ping Chang, 2012)[2], and the impact on impulsive purchasing behavior, and the results are not very consistent, there is few research conducting from online reviews receivers and their psychological perspective. We can learn from the cognitive psychology that consumers often filter and process information according to a specific way (Tversky A, 1974). Higgins (1997,2001) proposed regulatory focus theory which points out that some consumers are accustomed to thinking from the positive side, and some consumers are used to from the negative side, which will affect consumers' view on online comments and then affect their buying behavior[3]. Based on this theory, this article discusses the influence of online reviews on impulsive purchase behavior from the perspective of the online reviews receiver.

\section{Review of the Literature and hypotheses}

Impulse buying and network impulse buying. Rock and Fisher Rook, who in the 1980s began to clarify the nature of impulse buying, noted, "virtually every person, not a product has undergone impulse spending" and they defined consumer impulse buying as the spontaneous, immediate purchase behavior which lack of thinking (1995). It is the most commonly used definition in the present study as well as the basic of many researchers' further study and definition of the impulse buying behavior. In traditional shopping environment, the impulsive buying behavior is generally regarded as a behavior caused by environmental stimuli, personal traits, time, budget and so on. But there are a lot of difference between the network retail background and traditional retail background. 
For example, under the background of network retailing consumers can't touch and try products, but they can make up the defects through the commodity display, buyers' use experience, and the product recommendation system. As the auxiliary decision-making reason increasing, consumers will have more courage to make a buying decision (Tversky and Kahneman, 1974). LaRose (2001), as one of the earliest researchers of the network impulse buying, pointed out that product comments, suggestions and promotion can promote the non-binding network purchase. QinWu (2009) confirmed that online reviews are an important dimension affecting the network consumers' impulse purchase intention, and he also confirmed that the number, the form, the date and the content of the online comments will significantly impact on consumer impulse shopping network[4]. Chen xu, mei-hua Zhou (2010) build the mechanism model of the compulsive purchase behavior under the network environment by studying the formation mechanism of consumers' compulsive purchase behavior in the e-commercial environment[5]. And the impulsive purchasing behavior under the background of network is defined as a psychological reaction that consumers suddenly eager to get the goods immediately when online browsing because of the marketing stimulation. This kind of reaction prompts consumers to produce the unscheduled and immediate purchase intention which make its own instantaneous utility maximization. Their study enriched the research with a framework formed by the theory and the behavior of impulsive purchase under the background of network.

Online reviews. After Arndt (1967) clearly pointed out that word of mouth is an important variable influencing consumers' decision-making and behavior, word of mouth really caused the attention and in-depth research of scholars in the field of marketing. With the development of Internet, word-of-mouth spread to network space, forming online word of mouth. Online word of mouth (online word-of-mouth) is also known as electronic word of mouth (electronic word-of-mouth), mouse Monument (word-of-mouse) or online customer reviews.

Stephen, Ronald \& Bing (2007) believe that online reputation distinguishes from the traditional off-line word of mouth, and online reputation is a communication of information about all the specific characteristics of products and services and providers through network technology exchanging between consumers. Chen Yubo (2008) argues that online reviews, which acts as a free "marketing" function, are usually describe product attributes according to the usage of reviewers and reviews products performance from the perspective of the user, which can help consumers especially novices of network shopping to find the products which can meet their specific needs. Zhang Li (2011) make a more comprehensive definition of online word of mouth that the masses can get potential, real evaluations of the quality of goods, services, and enterprise and experiences of using a product or service, which are mainly in the form of text, via the Internet, positive or negative. And according to the report of CNNIC one can learn that online users accounts higher ratio of undergraduate degrees at $35.9 \%$, and taobao is most attractive to young online users; therefore, this article, based on the above concepts, takes online customer reviews of goods C2C website on such as taobao as the main research object and takes college students to target groups.

The influence of online reviews on impulsive purchase behavior. As one of scholars who earlier addressed the marketing value of online reviews, Chatterjee (2011) first proposed that online reviews made possible impact on consumers shopping from a marketing perspective[6]. Chatterjee (2001) thinks that with a high transparency of network information, consumers can research any relevant product information based on their require, and then make their buying decisions, which takes more advantage than traditional word of mouth whether in the accessibility, scope, source and time. And he believes that online comments will affect the receiver's cognition, beliefs, attitudes and actual decisions. Through the empirical study, ScWndler and others found that the motivation of consumers to search and read online word-of-mouth are Entertainment motivation and support motivation (Entertainment Motives). Many consumers focus on Internet word of mouth is just for fun or want to seek support for his decision has been made via the Internet word of mouth. They are keen to see interesting story of the comments, because they think watching information exchange is a funny thing. At the same time, they will therefore know the support motive of products or services which is discussed and learned. So when consumers read positive comments, 
the number of degree of online reviews may stimulate their impulsive purchase. (ya-ping chang, 2012). There are also studies showing that when it comes to the word of mouth consumer familiar with, impacts of both positive and negative word of mouth on consumers' attitude toward the product is the same (Ahluwalia). So what explains this inconsistency at the same time to have a complete understanding of the problem needs further research. At the same time, as one online comment text comments, it is not only characterized by information of the positive and negative comment but also includes double mixed information: a online comments might involve multiple aspects, such as products, services, logistics; consumers may not completely satisfy or dissatisfy all aspects, and they may satisfy some aspects and dissatisfy other aspects, thus the positive and negative mixed double comments come out. It also needs further research on the effectiveness of the hybrid information and the influence on impulsive purchasing behavior. So this article puts forward the following hypothesis: $\mathrm{H}$ : positive online reviews positive influence on Impulse purchase intention.

Regulatory focus theory. Humans instinctively seek happiness, according to which psychology has explained the intrinsic motivation of human behavior. At the end of the 20th century, however, Higgins, an American psychologist, put forward a new theory to explore the intrinsic motivation of human behavior. The theory thought that in the process of socialization the individual gradually formed its own unique control system which makes the different individuals in the same situation produce different ways of self-directed. And all individuals are divided into two categories: some people are more focus on the positive results of things, and they tend to achieve positive results. These people performed to be the marching type of regulatory focus and they hope the result is expressed by the maximization goal. The other people focus more on the negative consequences of things, and they tend to avoid negative consequences; the performance of them is prevention focus and they hope results are to minimize target. Differences of customer's regulatory focus can lead to the differences of thinking mode. Individuals of the marching type of regulatory focus are more likely to focus on positive comment, and people of the preventive adjusting focus tend to pay more attention to negative information (QiQingBo, 2008; Cao Xingmin, 2012)[7]. For the double mixed information, the individual of the marching type of regulatory more easily focus on positive information than people of the preventive adjusting focus. Consumers' judges on the matching degree of adjusting focus can affect whether the online reviews information will hinder or promote consumers' purchase decisions. Therefore, this paper argues that as for the promoted orientation of the individual, positive online reviews information affects the impulsive purchase intention while for individual prevention orientation, negative comments online information negative impact impulse purchase intention. But to promoted individual orientation, negative information online reviews and impulsive purchase intention, no significant relationship between for prevention of directional individual positive online reviews information with no significant relationship between compulsive purchase behavior, but also for double mixed information, promote the orientation of the individual's impulsive purchase intention is stronger than individual prevention orientation.

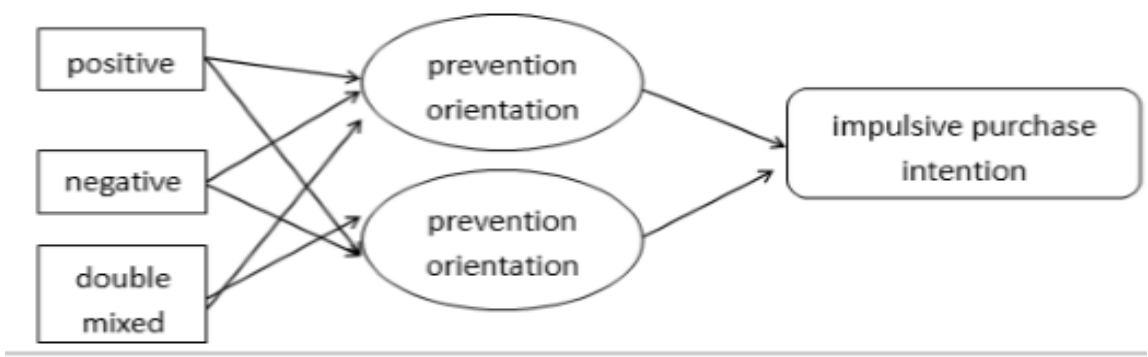

Fig 1 impact of online reviews on impulsive buying intention

\section{The results discussed}

Through literature review, this article summarizes the former research and gets a conclusion that impulsive purchase intention can be affected by the online comments. At the same time, in the 
process of reading literature, the writer found there are a lot of contrary conclusions in the study of online reviews' influence on impulsive purchase. Thus this study, from the perspective of psychology, uses the theory of adjusting orientation to analyze the mechanism of this effect deeply, which lays the foundation for follow-up study.

\section{References}

[1] China Internet Network Information Center (CNNIC). (2014). China's internet development state statistic report, Retrieved 12, 2013, from http://wenku.baidu.com/view.

[2] Y.P. Chang. The Influence Mechanism of Third-Party Product Reviews (TPRs) on Impulse Buying Intention Within the Internet Environment: by Product Category and Commentators Rank for Regulation Variables. Acta Psychologica Sinica. 2012, Vol. 44, No.9, 1244-1264.

[3] Higgins,E. T., Friedman, R. S., \& Harlow, R. E., et al. Achievement orientations from subjective histories of success: Promotion pride versus prevention pride. European Journal of Social Psychology, 2001,31:3-23

[4] Q. Wu. An Empirical Research on Mechanism of Online Review and Internet Consumer Impulse Buying Intent. Huazhong University of Science\&Technology,2009,5.

[5] C. Xu. An Exploratory Study on Formation Mechanism of Consumer's Impulse Purchase under the Ecommerce Environment. Economy and Management.Vol.24.,2010,10.

[6] Chatterjee, P. (2001). Online review: Do consumers use them? Advances in Consumer Research, 28, 129-133.

[7] Q.B. Qi. Exploring the mechanism of impulsive purchasing based on regulatory focus theory. Huazhong University of Science \&Technology,2008,4. 